\title{
La contaminación atmosférica: un contexto para el desarrollo de competencias en el aula de secundaria
}

\section{Air pollution: a context for the development of competencies in the secondary classroom}

\author{
Teresa Lupión Cobos \\ Facultad de Ciencias de la Educación. Universidad de Málaga \\ teluco@uma.es \\ Teresa Prieto Ruz \\ Facultad de Ciencias de la Educación. Universidad de Málaga \\ ruz@uma.es
}

RESUMEN • Este trabajo se centra en el estudio del aprendizaje de un grupo de estudiantes de edades comprendidas entre 16 y 18 años mientras realizaban actividades sobre un problema real y cercano, como es el de la calidad del aire en las ciudades. Se han definido indicadores para las diferentes competencias implicadas y cuatro niveles de desarrollo en ellas. El proceso de enseńanza y aprendizaje se llevó a cabo utilizando materiales seleccionados, que fueron desarrollados específicamente para tratar este problema. Los resultados ponen de manifiesto un progreso evidente principalmente en aquellos aspectos más relacionados con lo que los estudiantes tienen que enfrentar en su vida, más allá de las paredes de la escuela.

PALABRAS CLAVE: competencias; investigación en el aula; contexto; contaminación del aire; actitudes.

ABSTRACT - This paper focuses on the study of the learning progress of a group of students aged between 16 and 18, while they were performing activities on a real and close problem, as is the quality of the air in cities. Indicators for the different competencies involved, and 4 levels of development in them have been defined. The teaching and learning process was carried out by applying selected materials which were developed specifically to treat this problem. The results show clear progress mainly in those aspects related to what students have to face in their lives beyond school walls.

KEYWORDS: competencies; research in the classroom; context; air pollution; attitudes. 


\section{INTRODUCCIÓN}

En la actualidad, se suele denominar a la enseñanza de las ciencias y la tecnología durante la enseñanza obligatoria como: «Alfabetización Científica y Tecnológica» (Jenkins, 1999; De Boer, 2000 y Fensham, 2002). Para Sadler y Zeidler (2009), tal denominación engloba a dos grandes grupos de objetivos. El primero, referido al conocimiento científico escolar tradicional, es decir el de los procesos y los productos de la ciencia (conceptos y procedimientos científicos). El segundo se nutre de los componentes de situaciones reales que afectan a la ciudadanía, y en las que la ciencia y la tecnología se ven involucradas. El conocimiento, en este grupo, se refiere a la ciencia necesaria en situaciones en las que otros componentes de conocimiento juegan un papel importante. Es aquí donde se hacen más necesarias especificaciones sobre lo que hay que hacer para promover en el alumnado tal alfabetización. Según Sadler y Zeidler (2009), el modelo de alfabetización científica al que tendemos en nuestros días es uno que, aceptando el componente del primer grupo (siempre atendido por la enseńanza tradicional), se mueve cada vez con más seguridad hacia la incorporación de los componentes del segundo.

\section{MARCO TEÓRICO}

La relevancia y la conveniencia de una enseńanza y un aprendizaje de las ciencias, en los que la ciencia sea considerada conjuntamente con otros componentes de conocimiento, que juegan papeles importantes en los problemas reales que se dan en la sociedad, son reconocidas por numerosos autores (como Ratcliffe, 1997; Thomas, 2000; Millar, 2006; Roth y Lee, 2004; Holbrook y Rannikmae, 2007; Sadler, 2009; Sadler y Zeidler, 2009 y Prieto y España, 2010).

Este reconocimiento lleva a poner énfasis en la importancia de aquellas actividades que permiten al alumnado vivir la ciencia en contextos idénticos o análogos a aquellos que ellos tienen que confrontar en su vida, más allá de las paredes de la escuela. Actividades de aprendizaje capaces de mostrar problemas reales que los estudiantes puedan reconocer como tales y como propios y que, por ello, tienen un alto potencial de generar interés, motivación e iniciativa para aprender (Sauvé, 2010).

Por otra parte, el análisis de estos problemas pone de manifiesto elementos que van más allá de las fronteras de la ciencia tradicional, y que el profesorado de ciencias no debe pasar por alto (Banet, 2007 y 2010).

En el mismo sentido, se muestran los documentos de PISA (OECD, 2007a) según los cuales una ciudadanía preparada para hacer frente a los desafíos del futuro debe saber analizar, razonar y comunicar de manera efectiva y tener la capacidad de continuar aprendiendo a lo largo de la vida. Aspectos fundamentales en los que el esquema de PISA se centra son: el contexto en el que se insertan las actividades; las competencias que los estudiantes han de aplicar, y el conocimiento y las actitudes que ponen en juego (OECD, 2007b). Entre los dominios de contenidos prioritarios, destacan los problemas ligados a los recursos naturales y al medioambiente.

En España, el contenido del currículo de ciencias (MEC, 2007 y CEJA, 2007) asume estas propuestas, llevando a primer plano preguntas clave e intemporales en la educación científica como: ¿qué es importante que el alumnado aprenda?, ¿cómo enseñar los contenidos seleccionados?, o ¿cómo evaluar los aprendizajes alcanzados? (Prieto, España y Martín, 2012). Se trata de preguntas que el profesorado de ciencias ha de "traducir» y poner en los términos de la realidad que vivimos, con el fin de dar las respuestas más pertinentes a las necesidades de aprendizaje del alumnado (Cañas, Martín-Díaz y Nieda, 2007) y poder avanzar en el desarrollo de una adecuada competencia científica (Lupión y Prieto, 2005 y 2007) dentro de los objetivos generales de la educación obligatoria.

Este marco abre el camino a la consideración de un enfoque de la enseñanza dirigido a promover, en nuestro alumnado, la capacidad de utilizar el conocimiento científico y tecnológico en contextos 
cotidianos, aplicar los conocimientos y los procesos que caracterizan a las ciencias y a la tecnología y desarrollar la conciencia del papel que estas ejercen en la sociedad, tanto en la solución de problemas como en la génesis de nuevos interrogantes.

Se trata de un planteamiento en el que se pone el énfasis en procesos como la identificación y formulación de problemas, la selección, recogida e interpretación de información o la formulación de conclusiones, todo en el contexto de las experiencias que puede vivir la gente normal en su vida cotidiana, en situaciones que ejemplifican la "ciencia en la acción», una ciencia que algunos autores han venido a denominar ciencia de la ciudadanía (Schibeci y Lee, 2003; Roth y Lee, 2004 y Sauvé, 2010).

\section{CONTEXTO Y PREGUNTAS DE INVESTIGACIÓN}

El trabajo que aquí se presenta es el resultado de una investigación en el aula. Como nivel educativo, se seleccionó un aula de primero de bachillerato y como tema, uno cercano y de interés para el alumnado: «la calidad del aire en las ciudades», articulada según unas actividades llevadas a cabo por los alumnos.

La investigación se desarrolló durante la enseñanza sobre el bloque temático de «La contaminación». En este bloque se estudiaban los aspectos específicos de esta relativos a la contaminación atmosférica, contaminación del agua, contaminación radiactiva y contaminación acústica. Dentro del él, el alumnado ha podido hacer valoraciones y propuestas sobre aspectos relevantes de la contaminación como fenómeno global.

El enfoque ha respondido a la idea de que es preciso partir de problemas concretos que el alumnado puede encontrar en su entorno y, a partir de ahí, desde una perspectiva interdisciplinar, integradora y que promueva el espíritu crítico, establecer las interrelaciones necesarias.

La metodología ha estado centrada en el alumnado como protagonista de su propio proceso de aprendizaje y en la labor del docente como facilitador de este, con funciones de coordinación, seguimiento y evaluación.

El tratamiento de esta unidad se ha insertado en el desarrollo de una asignatura optativa de enfoque CTS con horario lectivo de 3 horas semanales, dentro del bloque de contenidos «Repercusiones sociales del desarrollo científico y técnico», incorporando aspectos relacionados con el «Impacto directo sobre el medio ambiente» y con el «Control social de la actividad científica y tecnológica».

La implementación de la unidad se realizó en el segundo trimestre del curso, una vez que el alumnado se familiarizó con la metodología de trabajo y se incorporó contenidos básicos relacionados con el enfoque Ciencia, Tecnología y Sociedad.

El estudio, que consistió en el seguimiento del proceso de enseñanza-aprendizaje, se llevó a cabo utilizando materiales elaborados y seleccionados específicamente para el tratamiento de este problema (Boyano et al., 2005). Con él se pretendía conocer, analizar y describir, lo más pormenorizadamente posible, el aprendizaje que este alumnado alcanza, expresado en función de las competencias que se ponen en juego con el proceso de enseñanza y los materiales antes indicados.

En este trabajo, tratamos de buscar respuestas a las siguientes preguntas:

1. ¿Qué oportunidades ofrecen las actividades estudiadas para el desarrollo de competencias en el alumnado?

2. ¿Cuál es el grado de progreso de un grupo de alumnos, en términos de competencias, después de realizar las actividades estudiadas? 


\section{Material aplicado}

El material aplicado, de título: La calidad del aire en las ciudades, está formado por cinco actividades (cuadros 1, 2, 3 y 4). Este material, de marcado carácter interdisciplinar, forma parte de una unidad más amplia relativa a la contaminación atmosférica, en cuyo diseño se han utilizado materiales de confección propia (Lupión y Prieto, 2005) y otros recursos procedentes del material educativo (WWW/ Adena, 1998). Este material, que se caracteriza por ser multimedia, permite acceder al Informe Dobris editado por la Agencia Europea de Medio Ambiente y se estructura en cuatro áreas: Aguas continentales, Mares y Costas, Bosques y Zonas Urbanas. Las actividades seleccionadas se centran en el área Zonas Urbanas y ponen un énfasis especial en demandar al alumnado la aplicación de conocimientos e ideas científicas a la comprensión y actuación de este problema actual que tanto les afecta, así como promover la participación activa del alumnado y su colaboración con otros estudiantes.

\section{Cuadro 1.}

Esquema del material relativo a la Calidad del aire en las ciudades

Calidad del aire en las ciudades

* Objetivos:

Investigar la contaminación causada por el tráfico en zonas urbanas.

Considerar formas de reducir el tráfico para mejorar la calidad del aire.

* Material Necesario:

Hojas de recursos (cuadros 2, 3 y 4 ).

Boletín informático: Londres: calidad del aire, Calidad del aire: Moscú, Calidad del aire: Atenas, Automóviles: ¿amigos o enemigos?

Mapa a gran escala de la zona.

* Método. Actividades:

Actividad 1. La clase examinará la información sobre la calidad del aire que aparece en el Boletín informático y en la Hoja de recursos. Establecerán la relación entre las características geográficas de una zona y la climatología con el impacto que las emisiones de humo ejercen sobre la calidad del aire en las ciudades.

Actividad 2. El alumnado examinará la información del Boletín informático: Automóviles: ¿amigos o enemigos?, para enumerar el porcentaje de cada contaminante producido por el transporte por carretera del más al menos perjudicial.

Actividad 3. En pequeños grupos, comentarán sugerencias para la reducción de vehículos a motor presentadas en el Boletín informático y en la Hoja de recursos.

Actividad 4. Los estudiantes elegirán una carretera o zona congestionada en el área próxima a su centro. En pequeños grupos, diseñarán un plan para la gestión del tráfico que tome en consideración las necesidades de todos los sectores de la comunidad.

Actividad 5. Esta información se intercambiará con otros centros y se valorará la calidad atmosférica de cada zona. 
Cuadro 2.

Smog en verano y en invierno

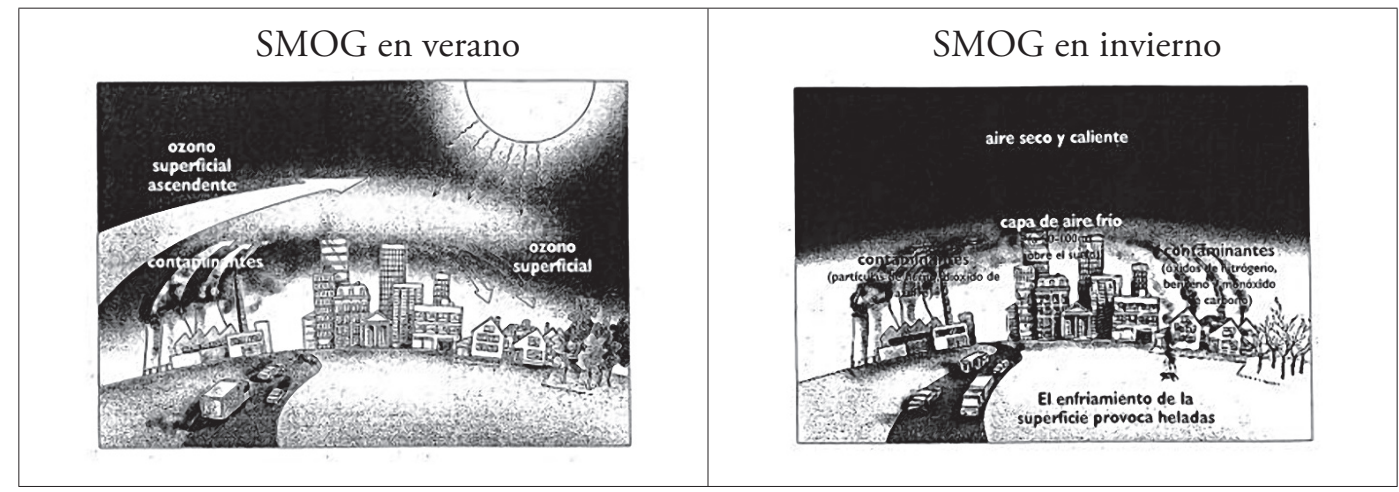

(Folleto producido por el Departamento de Medio Ambiente, julio 1995. Crown Copyright. Reproducido con el permiso de Her Majesty's Stationery Office)

Cuadro 3.

Calidad del aire en las ciudades

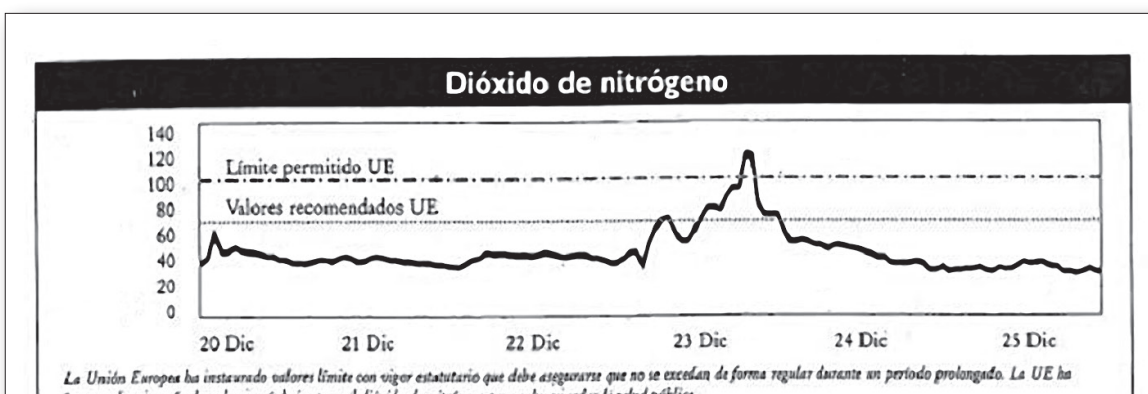

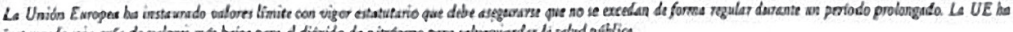

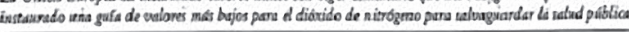
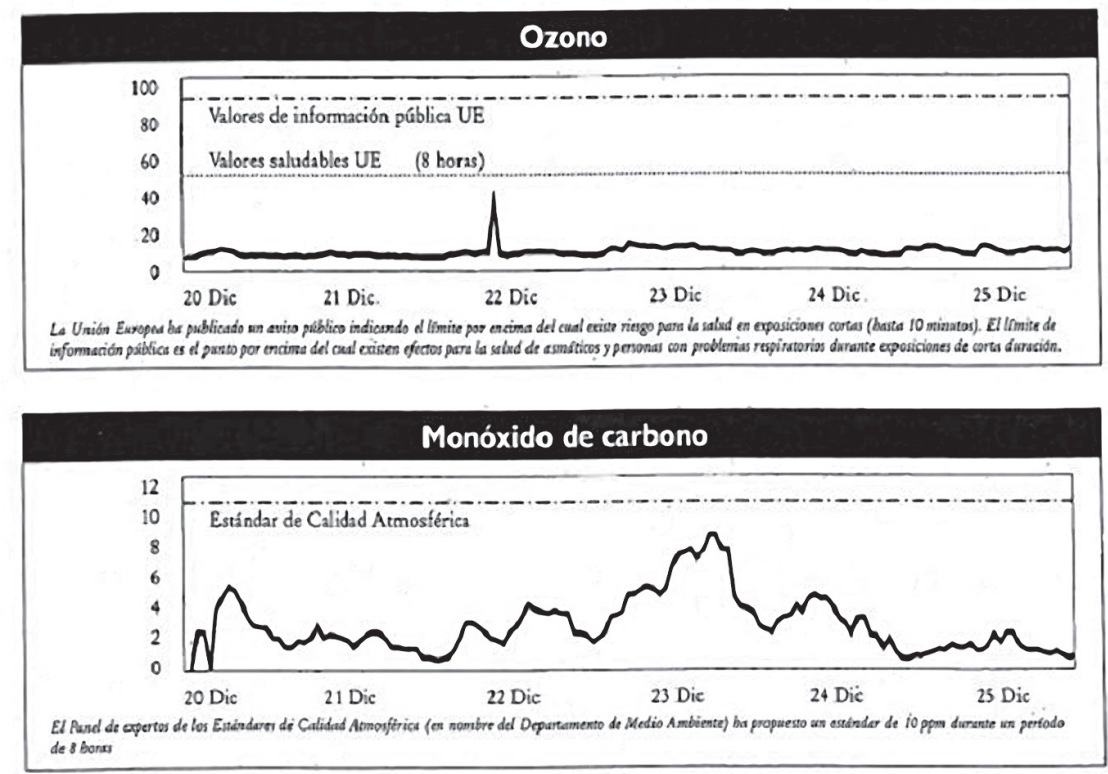

Reproducido de Air quality bulletins, Hackney. 
Cuadro 4.

Circulación humana

\section{Movilizar a un millón de personas: ¡cómo hacerlo?}

A continuación se reseñan situaciones en las que se puede aprovechar la oportunidad de promocionar un decreto para la reducción del tráfico rodado.

1.- En todos los lugares donde se repitan las quejas por el exceso de tráfico, podrá enfatizarse la relevancia de este decreto mencionando que es la única solución real y permanente para reducir el tráfico, mejorar el transporte público y todo lo demás.

2.- Cada calle o ciudad congestionada por el tráfico es terreno fértil; nuevamente, la única solución real para la congestión es la reducción de tráfico.

3.- En cualquier carretera donde los vecinos se quejen por la lentitud del tráfico o aparcamiento indebido, mencionadles que se podrían evitar con la reducción del tráfico.

4.- En cualquier momento en el que se exprese preocupación sobre la calidad atmosférica o la contaminación, recordad que se necesita una reducción del tráfico.

5.- Cuando se exprese una preocupación por el asma o la bronquitis, relacionadlo con el tráfico y la necesidad de su reducción.

6.- Siempre que se mencione la preocupación por los accidentes o la seguridad de los niños en su camino al colegio, puntualizad que la reducción del tráfico por carretera reduciría el peligro.

7.- En aquellos lugares en los que los comerciantes se quejen porque sufren debido a que las grandes superficies o hipermercados están en las afueras de la ciudad, recordadles que la reducción del tráfico beneficiaría a los comercios locales y las comunidades.

8.- Siempre que surja la preocupación porque una nueva carretera destrozará un paraje o hábitat natural o una comunidad local, presentad el decreto como una forma a largo plazo de evitar la amenaza de la construcción de carreteras.

9.- Siempre que se muestre preocupación por el ruido del tráfico, dejad bien claro que solo la reducción del tráfico llevará un poco de paz a nuestras vidas de nuevo.

10.- De hecho, existen cientos de situaciones habituales en las que la reducción del tráfico es la única solución real. No perdáis ninguna oportunidad.

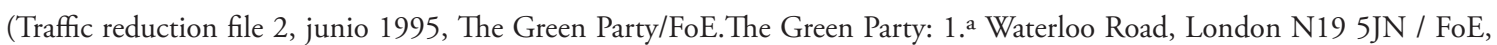
26-28 Underwood street, London N 1 7JQ)

\section{Muestra}

Esta investigación se ha desarrollado en el contexto de una clase de 20 alumnos y alumnas de edades comprendidas entre 16-18 años que cursaban primero de bachillerato en un instituto de educación secundaria en una zona urbana de la ciudad de Málaga. La primera parte, un estudio piloto, los ha implicado a todos, y la segunda se ha centrado en el trabajo de un grupo constituido por cuatro estudiantes, dos chicas y dos chicos, con un rango de habilidades representativo del que muestra la clase.

\section{RECOGIDA Y ANÁLISIS DE DATOS}

La recogida de información durante el desarrollo de la unidad se realizó mediante:

- protocolos de observación en el aula,

- registros de intercambios entre centros de comunicación sincrónica y asincrónica entre el alumnado y

- entrevistas. 


\section{Competencias e indicadores}

El diseño de protocolos de observación estuvo guiado por: en primer lugar, consideraciones de los investigadores sobre las competencias puestas en juego en todas las actividades y, en segundo lugar, una prueba piloto en la que se observaron las competencias puestas en juego por todo el alumnado de la clase en la realización de las actividades 1, 2 y 3. A partir de ahí, se diseñó un protocolo de observación en el que se tuvieron en cuenta las actuaciones que el alumnado implicado realiza en todos y cada uno de los procesos de cada actividad y se definieron indicadores para las competencias consideradas (cuadro 5).

\section{Cuadro 5 .}

Indicadores de competencias en las actividades

\begin{tabular}{|c|c|}
\hline Competencia & Indicador \\
\hline 1. Comprensión lectora. & $\begin{array}{l}\text { Identificar el significado de las ideas en un texto que utiliza terminología } \\
\text { y expresiones científicas. }\end{array}$ \\
\hline 2. Exponer y argumentar verbalmente. & $\begin{array}{l}\text { Establecer relaciones para sustentar las afirmaciones utilizando las ideas } \\
\text { clave necesarias. }\end{array}$ \\
\hline 3. Comunicación escrita. & Utilizar terminología científica en la expresión. \\
\hline $\begin{array}{l}\text { 4. Aplicar conocimientos en contextos diver- } \\
\text { sos. }\end{array}$ & Realizar observaciones identificando y formulando cuestiones científicas. \\
\hline $\begin{array}{l}\text { 5. Analizar y sintetizar informaciones de tex- } \\
\text { tos. }\end{array}$ & $\begin{array}{l}\text { Identificar las ideas clave de un texto expresando las relaciones científicas } \\
\text { implicadas. }\end{array}$ \\
\hline 6. Extraer información de tablas y gráficos. & Localizar y obtener información cualitativa y cuantitativa. \\
\hline 7. Trabajar en equipo. & $\begin{array}{l}\text { Actuar cooperativamente en la realización de tareas e intercambio de in- } \\
\text { formación en un colectivo. }\end{array}$ \\
\hline $\begin{array}{l}\text { 8. Mostrar conocimientos básicos y específi- } \\
\text { cos. }\end{array}$ & $\begin{array}{l}\text { Desarrollar y aplicar el conocimiento científico para interpretar la infor- } \\
\text { mación recibida. }\end{array}$ \\
\hline 9. Investigación: establecer relaciones. & Identificar y relacionar variables. \\
\hline 10. Investigación: buscar información. & $\begin{array}{l}\text { 10. Encontrar y seleccionar datos pertinentes de fuentes fiables y diversas } \\
\text { extrayendo información significativa y formulando conclusiones. }\end{array}$ \\
\hline 11. Investigación: formular conclusiones. & Coherencia y relevancia de formulaciones. \\
\hline 12. Preocupación por la calidad. & Valoración del trabajo desarrollado. \\
\hline 13. Adaptación a nuevas situaciones. & $\begin{array}{l}\text { Gestionar situaciones presentadas aplicando conocimientos y haciendo } \\
\text { propuestas concretas. }\end{array}$ \\
\hline 14. Motivaciones de logro. & Dar valor a la realización de tareas y/o cumplimiento de objetivos. \\
\hline 15. Creatividad. & $\begin{array}{l}\text { Iniciativa en la toma de decisiones fundamentadas asociadas a situaciones } \\
\text { nuevas. }\end{array}$ \\
\hline 16. Autonomía en el desarrollo de actividades. & Planificar la ejecución de tareas propuestas con iniciativa propia. \\
\hline 17. Gestión de la información. & Analizar y presentar datos pertinentes y relevantes. \\
\hline $\begin{array}{l}\text { 18. Conocimiento práctico de aplicaciones } \\
\text { con ordenador. }\end{array}$ & $\begin{array}{l}\text { Realizar, desde sistemas informáticos, acciones que permiten extraer y/o } \\
\text { presentar información a través de: a) tablas, gráficos, etc.; b) imágenes, } \\
\text { vídeos, sonidos, c) modificar/crear una página web. }\end{array}$ \\
\hline 19. Habilidades derivadas del uso de Internet. & $\begin{array}{l}\text { Realizar actuaciones concretas como: a) enviar mensajes electrónicos y/o } \\
\text { participar en un chat; b) adjuntar ficheros y/o incluir enlaces; c) utilizar } \\
\text { un buscador, d) descargar imágenes, vídeos y sonidos. }\end{array}$ \\
\hline
\end{tabular}

Los registros de intercambios entre centros de comunicación sincrónica y asincrónica corresponden a la relación establecida por el grupo de alumnos en estudio con otro grupo procedente de otro centro 
educativo, cuando realizaban las actividades relativas a la confección de un plan de calidad atmosférica de la zona y el intercambio y análisis de los planes respectivos (actividades 4 y 5 ).

Las entrevistas personales (una por estudiante) se llevaron a cabo tras la realización de las actividades, en el propio contexto de clase, a los cuatro componentes del grupo estudiado. No se organizaron mediante protocolo, sino de manera informal y personalizada, de forma que a cada uno se le preguntó por aquellos aspectos en los que menos se había manifestado durante la realización de la actividad.

\section{Qué hace el alumnado cuando trabaja en equipo y qué observa el profesorado}

El desarrollo de las clases arranca con un planteamiento inicial al alumnado, en forma de lectura introductoria, que permite al profesorado sondear sus ideas previas y despertar su curiosidad y motivación por el estudio del problema. A continuación, tiene lugar la secuencia de actividades en grupo, que ha sido objeto de observación por parte de la profesora investigadora en el aula.

Los participantes comienzan analizando la información de la Hoja de recursos. Tienen que tomar nota y valorar las concentraciones de los distintos contaminantes primarios (dióxido de nitrógeno, ozono, monóxido de carbono, etcétera) en las diferentes ciudades. Deberán cotejar estos datos con sus características (ubicación geográfica, climatología y urbanismo, cuadro 2).

Identificar e intercambiar información entre los componentes de cada grupo implica comprensión lectora y expresión verbal. Se aplican conocimientos básicos y específicos sobre la química del aire en sus vertientes relativas a las actuaciones de contaminantes primarios, contaminantes secundarios y las diferencias entre el smog fotoquímico e invernal. Se emiten juicios, resultado del análisis y síntesis de la situación.

Examinar información del Boletín informático implica habilidades relacionadas con la gestión de la información y con la obtención y el manejo de esta usando el ordenador. Durante este examen, los alumnos se distribuyen las tareas y realizan puestas en común en el seno del grupo; en ellas, se ponen en juego la comunicación oral y escrita, la comprensión lectora, la expresión verbal, el análisis e interpretación de las tablas y gráficos y el intercambio de información sobre la calidad del aire de las ciudades estudiadas: Atenas, Londres y Moscú.

A partir de la información recogida y analizada, los estudiantes tienen que establecer relaciones entre las características geográficas y climatológicas de la zona y su impacto en las emisiones y en la calidad del aire. Aquí se dan oportunidades para aplicar conocimientos de los entornos seleccionados: costumbres de comportamiento en los desplazamientos; usos de transportes, públicos o privados; horarios de desplazamientos; población implicada; urbanismo de las ciudades; ubicación geográfica; orografía y clima, y demografía, etcétera. Se trata de un conocimiento interdisciplinar que resulta tan necesario como el conocimiento científico implicado, como: contaminantes primarios y secundarios; sus concentraciones; su permanencia en el ambiente, etcétera. La consideración conjunta de todos estos elementos debe estimular la necesidad de plantear y realizar una investigación en el grupo, poniendo en juego creatividad y trabajo en equipo y dando sentido a la selección, organización e integración del conocimiento analizado.

La actividad 2 requiere el uso del Boletín informático Automóviles: ¿amigos o enemigos? para enumerar el porcentaje de cada contaminante producido por el transporte por carretera, y se centra, específicamente, en el análisis de información procedente de gráficos (tabla 3). En la actividad 3, los participantes ponen en común propuestas y sugerencias para la reducción de vehículos a motor, presentadas en el Boletín informático y en la Hoja de recursos. En ella, se pone en juego el análisis de situaciones específicas que conllevan el espíritu crítico, la creatividad, la preocupación por la calidad y la autonomía. En ambas actividades, se aplican competencias relativas a la gestión de información y al manejo del ordenador. 
El debate sobre la valoración «vehículos a motor-comodidad-libertad» frente a «vehículos a motorcontaminación atmosférica» entre los grupos de trabajo, con el que termina la actividad 3, favorece el trabajo en equipo, la expresión oral, la argumentación, la exposición de ideas, la comunicación oral y escrita, la aplicación de conocimientos a situaciones concretas de la práctica y la síntesis global; competencias a las que se ańaden el compromiso ético, la capacidad de generar ideas con propuestas concretas y la adaptación a nuevas situaciones.

En la actividad 4, los participantes, después de elegir una carretera o un lugar próximo a su centro, diseńan, en grupo, un plan para gestionar el tráfico, y valoran las necesidades de las zonas. En su primera parte, esta actividad requiere: en primer lugar, consultas del mapa de la zona; en segundo lugar, desplazamientos a puntos críticos, y por último, la valoración de la densidad de población, de la ubicación y regulación de semáforos, de la disposición de las distintas zonas (comerciales, educativas, residenciales, etcétera.), de los sentidos de circulación del tráfico, etcétera. Se trata de un «hacerse cargo" del contexto real en el que se está estudiando el problema, y de los distintos factores que pueden tener incidencia en él, así como el peso relativo que tienen.

El desarrollo de esta actividad, además del trabajo en equipo y la organización y planificación, promueve las motivaciones individuales, el espíritu emprendedor, la adaptación a nuevas situaciones, la preocupación por la calidad, el compromiso ético, la generación de ideas, la transferencia, la aplicación de conocimientos en la práctica, la toma de decisiones y las propuestas de resolución del problema.

Estas propuestas quedan materializadas en la redacción del correspondiente informe, el cual permite aunar, además de la comunicación oral y escrita, el conocimiento práctico de la comunicación electrónica: sistemas operativos, procesador de textos, elaboración de tablas, gráficos y/o imágenes, las competencias básicas de consulta de la red informática: búsqueda y selección de información, almacenamiento y recuperación de datos, etcétera, y otras de gran interés en la sociedad teleinformada actual como: enviar mensajes electrónicos, adjuntar ficheros, incluir enlaces, utilizar un buscador, participar en un chat, bajar archivos, crear/modificar una página web, diseñar presentaciones multimedia.

Finalmente, la actividad 5 consiste en el intercambio, con otro grupo, de un centro diferente, pero de otra zona de la misma ciudad, de sus respectivos planes de actuación.

Esta actividad, centrada en «Investigar la contaminación causada por el tráfico en zonas urbanas» $\mathrm{y}$ «Considerar formas de reducir el tráfico para mejorar la calidad del aire», incorpora las posibilidades que nos ofrece Internet. De esta manera, no solo aumenta la rapidez y la efectividad de la comunicación, sino que se amplían las perspectivas de los alumnos, algo muy conveniente si tenemos en cuenta que, en un problema global como este, no solo necesitamos conocimiento, sino también actitudes, valores y concienciación ciudadana, tanto a nivel individual como colectivo.

En la tabla 1, se recogen las competencias que hemos considerado que están implicadas en las cinco actividades objeto de estudio. 
Tabla 1.

Competencias implicadas en las actividades

\begin{tabular}{|c|c|c|c|c|c|}
\hline \multirow{2}{*}{ Competencias } & \multicolumn{5}{|c|}{ Actividades } \\
\hline & A1 & $\mathrm{A} 2$ & A3 & A4 & A5 \\
\hline 1. Comprensión lectora & $\mathrm{x}$ & $\mathrm{x}$ & $\mathrm{x}$ & & $\mathrm{x}$ \\
\hline 2. Exposición y argumentación verbal de ideas & $\mathrm{x}$ & $\mathrm{x}$ & $\mathrm{x}$ & $\mathrm{x}$ & $\mathrm{x}$ \\
\hline 3. Comunicación escrita & $\mathrm{x}$ & & & $\mathrm{x}$ & $\mathrm{x}$ \\
\hline 4. Aplicar conocimientos en contextos diversos & $\mathrm{x}$ & $\mathrm{x}$ & $\mathrm{x}$ & $\mathrm{x}$ & $\mathrm{x}$ \\
\hline 5. Analizar y sintetizar informaciones de textos & $\mathrm{x}$ & $\mathrm{x}$ & $\mathrm{x}$ & $\mathrm{x}$ & $\mathrm{x}$ \\
\hline 6. Analizar información de tablas y gráficos & $\mathrm{x}$ & $\mathrm{x}$ & $\mathrm{x}$ & & $\mathrm{x}$ \\
\hline 7. Trabajar en equipo & $\mathrm{x}$ & & $\mathrm{x}$ & $\mathrm{x}$ & $\mathrm{x}$ \\
\hline 8. Mostrar conocimientos básicos y específicos & $\mathrm{x}$ & & & $\mathrm{x}$ & \\
\hline 9. Investigación: establecer relaciones & $\mathrm{x}$ & & & $\mathrm{x}$ & \\
\hline 10. Investigación: realizar búsquedas de información & $\mathrm{x}$ & & & $\mathrm{x}$ & $\mathrm{x}$ \\
\hline 11. Investigación: formular conclusiones & $\mathrm{x}$ & & & $\mathrm{x}$ & \\
\hline 12. Preocupación por la calidad & & & $\mathrm{x}$ & $\mathrm{x}$ & $\mathrm{x}$ \\
\hline 13. Adaptación a nuevas situaciones & & & $\mathrm{x}$ & $\mathrm{x}$ & $\mathrm{x}$ \\
\hline 14. Motivaciones de logro & & & $\mathrm{x}$ & $\mathrm{x}$ & $\mathrm{x}$ \\
\hline 15. Creatividad & & & $\mathrm{x}$ & $\mathrm{x}$ & $\mathrm{x}$ \\
\hline 16. Autonomía en el desarrollo de actividades & & & $\mathrm{x}$ & $\mathrm{x}$ & $\mathrm{x}$ \\
\hline 17. Gestión de la información & $\mathrm{x}$ & $\mathrm{x}$ & & $\mathrm{x}$ & $\mathrm{x}$ \\
\hline 18. Aplicaciones con ordenador & $\mathrm{x}$ & $\mathrm{x}$ & & $\mathrm{x}$ & $\mathrm{x}$ \\
\hline 19. Habilidades derivadas del uso de Internet & & & & $\mathrm{x}$ & $\mathrm{x}$ \\
\hline
\end{tabular}

\section{Formulación de niveles de desarrollo en las competencias}

Durante la realización de las actividades, se llevó a cabo un seguimiento exhaustivo al grupo de estudio, tanto por la vía de la observación como de la atención a las conversaciones del alumnado mientras realizaban sus tareas, y se les realizaron entrevistas de manera informal, que consistieron en preguntas y respuestas sobre las tareas que estaban realizando en diferentes momentos. Como resultado, se diferenciaron cuatro niveles en cada una de las competencias establecidas (Lupión y Prieto, 2006). Para realizar esta asignación, se definieron y aplicaron los criterios recogidos en el cuadro 6. 


\section{Cuadro 6.}

Criterios para la determinación de niveles de desarrollo en las competencias

\begin{tabular}{|c|c|c|c|c|}
\hline Indicadores & Nivel 1 & Nivel 2 & Nivel 3 & Nivel 4 \\
\hline $\begin{array}{l}\text { 1. Identificar el } \\
\text { significado de las ideas } \\
\text { en un texto que utiliza } \\
\text { terminología y expre- } \\
\text { siones científicas. }\end{array}$ & $\begin{array}{l}\text { No entiende todas las } \\
\text { ideas del texto. }\end{array}$ & $\begin{array}{l}\text { Entiende algunas ideas } \\
\text { del texto. }\end{array}$ & $\begin{array}{l}\text { Entiende todas las } \\
\text { ideas del texto. }\end{array}$ & $\begin{array}{l}\text { Entiende todas las } \\
\text { ideas del texto incor- } \\
\text { porando términos } \\
\text { científicos apropiados } \\
\text { en su propio lenguaje. }\end{array}$ \\
\hline $\begin{array}{l}\text { 2. Establecer relacio- } \\
\text { nes para sustentar las } \\
\text { afirmaciones utili- } \\
\text { zando las ideas clave } \\
\text { necesarias. }\end{array}$ & $\begin{array}{l}\text { Plantea relaciones } \\
\text { insuficientes o no } \\
\text { pertinentes en la argu- } \\
\text { mentación que quiere } \\
\text { establecer. }\end{array}$ & $\begin{array}{l}\text { Plantea algunas rela- } \\
\text { ciones pertinentes en } \\
\text { la argumentación que } \\
\text { quiere establecer. }\end{array}$ & $\begin{array}{l}\text { Plantea relaciones } \\
\text { pertinentes en la argu- } \\
\text { mentación que quiere } \\
\text { establecer utilizando } \\
\text { una secuencia lógica } \\
\text { para la explicación. }\end{array}$ & $\begin{array}{l}\text { Plantea relaciones } \\
\text { pertinentes en la argu- } \\
\text { mentación que quiere } \\
\text { establecer utilizando } \\
\text { un lenguaje propio } \\
\text { pertinente y una } \\
\text { secuencia lógica para } \\
\text { la explicación. }\end{array}$ \\
\hline $\begin{array}{l}\text { 3. Utilizar termino- } \\
\text { logía científica en la } \\
\text { expresión. }\end{array}$ & $\begin{array}{l}\text { No utiliza un lenguaje } \\
\text { correcto para expresar } \\
\text { sus ideas. }\end{array}$ & $\begin{array}{l}\text { Utiliza un lenguaje } \\
\text { correcto para expresar } \\
\text { sus ideas pero no } \\
\text { siempre apropiado al } \\
\text { contexto seleccionado. }\end{array}$ & $\begin{array}{l}\text { Utiliza un lenguaje } \\
\text { correcto para expresar } \\
\text { sus ideas en contextos } \\
\text { diferentes. }\end{array}$ & $\begin{array}{l}\text { Utiliza un lenguaje } \\
\text { propio, científica- } \\
\text { mente preciso, para } \\
\text { expresar sus ideas en } \\
\text { contextos diferentes. }\end{array}$ \\
\hline $\begin{array}{l}\text { 4. Realizar observa- } \\
\text { ciones identificando y } \\
\text { formulando cuestiones } \\
\text { científicas. }\end{array}$ & $\begin{array}{l}\text { Las relaciones estable- } \\
\text { cidas no son correctas. }\end{array}$ & $\begin{array}{l}\text { Las relaciones esta- } \\
\text { blecidas son correctas } \\
\text { pero las cuestiones } \\
\text { científicas implicadas } \\
\text { están mal formuladas. }\end{array}$ & $\begin{array}{l}\text { Las relaciones esta- } \\
\text { blecidas son correctas } \\
\text { y están bien formu- } \\
\text { ladas algunas de las } \\
\text { cuestiones científicas } \\
\text { implicadas. }\end{array}$ & $\begin{array}{l}\text { Las relaciones esta- } \\
\text { blecidas son correc- } \\
\text { tas, responden a las } \\
\text { cuestiones científicas } \\
\text { implicadas, y quedan } \\
\text { todas bien formuladas. }\end{array}$ \\
\hline $\begin{array}{l}\text { 5. Identificar las ideas } \\
\text { clave de un texto ex- } \\
\text { presando las relaciones } \\
\text { científicas implicadas. }\end{array}$ & $\begin{array}{l}\text { Indica ideas no perti- } \\
\text { nentes. }\end{array}$ & $\begin{array}{l}\text { Identifica algunas } \\
\text { ideas clave utilizando } \\
\text { un lenguaje ajeno no } \\
\text { incorporado. }\end{array}$ & $\begin{array}{l}\text { Identifica algunas } \\
\text { ideas clave utilizando } \\
\text { un lenguaje propio. }\end{array}$ & $\begin{array}{l}\text { Identifica todas las } \\
\text { ideas clave utilizando } \\
\text { un lenguaje propio y } \\
\text { pertinente. }\end{array}$ \\
\hline $\begin{array}{l}\text { 6. Localizar y obtener } \\
\text { información cualitati- } \\
\text { va y cuantitativa. }\end{array}$ & $\begin{array}{l}\text { Identifica y encuentra } \\
\text { algunas relaciones } \\
\text { de proporcionalidad } \\
\text { entre las variables } \\
\text { implicadas en la infor- } \\
\text { mación. }\end{array}$ & $\begin{array}{l}\text { Identifica y encuen- } \\
\text { tra las relaciones de } \\
\text { proporcionalidad } \\
\text { existentes entre las va- } \\
\text { riables implicadas sin } \\
\text { poder calcular valores } \\
\text { indirectos. }\end{array}$ & $\begin{array}{l}\text { Identifica y encuen- } \\
\text { tra las relaciones de } \\
\text { proporcionalidad } \\
\text { existentes entre las } \\
\text { variables implicadas } \\
\text { pudiendo calcular } \\
\text { valores indirectos. }\end{array}$ & $\begin{array}{l}\text { Identifica y encuen- } \\
\text { tra las relaciones de } \\
\text { proporcionalidad } \\
\text { establecidas entre } \\
\text { variables implicadas } \\
\text { pudiendo calcular } \\
\text { valores indirectos y } \\
\text { extrapolando datos. }\end{array}$ \\
\hline $\begin{array}{l}\text { 7. Actuar cooperativa- } \\
\text { mente en realización } \\
\text { de tareas e intercam- } \\
\text { bio de información en } \\
\text { un colectivo. }\end{array}$ & $\begin{array}{l}\text { Participa a veces y } \\
\text { realiza algunas de las } \\
\text { acciones acordadas. }\end{array}$ & $\begin{array}{l}\text { Participa y realiza } \\
\text { algunas de las acciones } \\
\text { acordadas no ajus- } \\
\text { tándose siempre a las } \\
\text { normas y los plazos } \\
\text { establecidos. }\end{array}$ & $\begin{array}{l}\text { Participa y realiza las } \\
\text { acciones acordadas } \\
\text { pero no siempre se } \\
\text { ajusta a las normas y } \\
\text { los plazos establecidos } \\
\text { y sin aportar ideas } \\
\text { propias. }\end{array}$ & $\begin{array}{l}\text { Participa y realiza las } \\
\text { acciones acordadas } \\
\text { ajustándose a normas } \\
\text { y plazos establecidos } \\
\text { aportando ideas perti- } \\
\text { nentes. }\end{array}$ \\
\hline $\begin{array}{l}\text { 8. Desarrollar y aplicar } \\
\text { el conocimiento cien- } \\
\text { tífico para interpretar } \\
\text { la información que se } \\
\text { recibe. }\end{array}$ & $\begin{array}{l}\text { Establece bien algunas } \\
\text { de las relaciones cien- } \\
\text { tíficas implicadas en } \\
\text { las ideas aportadas. }\end{array}$ & $\begin{array}{l}\text { Establece bien las } \\
\text { relaciones científicas } \\
\text { implicadas en las ideas } \\
\text { aportadas. }\end{array}$ & $\begin{array}{l}\text { Establece bien las } \\
\text { relaciones científicas } \\
\text { implicadas en las ideas } \\
\text { aportadas sin poder } \\
\text { establecer cálculos o } \\
\text { correlaciones deriva- } \\
\text { dos. }\end{array}$ & $\begin{array}{l}\text { Establece bien las } \\
\text { relaciones científicas } \\
\text { implicadas en las ideas } \\
\text { aportadas realizando } \\
\text { cálculos y correlacio- } \\
\text { nes derivados. }\end{array}$ \\
\hline
\end{tabular}




\begin{tabular}{|c|c|c|c|c|}
\hline Indicadores & Nivel 1 & Nivel 2 & Nivel 3 & Nivel 4 \\
\hline $\begin{array}{l}\text { 9. Identificar y relacio- } \\
\text { nar variables. }\end{array}$ & $\begin{array}{l}\text { No identifica las } \\
\text { variables que hay que } \\
\text { consultar para estable- } \\
\text { cer sus respuestas. }\end{array}$ & $\begin{array}{l}\text { Identifica algunas de } \\
\text { las variables que hay } \\
\text { que consultar para es- } \\
\text { tablecer sus respuestas. }\end{array}$ & $\begin{array}{l}\text { Identifica todas las } \\
\text { variables que hay que } \\
\text { consultar para estable- } \\
\text { cer sus respuestas. }\end{array}$ & $\begin{array}{l}\text { Identifican todas las } \\
\text { variables que hay que } \\
\text { consultar para esta- } \\
\text { blecer sus respuestas } \\
\text { expresando de manera } \\
\text { precisa las relaciones } \\
\text { pertinentes. }\end{array}$ \\
\hline $\begin{array}{l}\text { 10. Encontrar y selec- } \\
\text { cionar datos pertinen- } \\
\text { tes de fuentes fiables } \\
\text { y diversas, extrayendo } \\
\text { información signifi- } \\
\text { cativa y formulando } \\
\text { conclusiones. }\end{array}$ & $\begin{array}{l}\text { Halla información } \\
\text { relacionada con la so- } \\
\text { licitada en fuentes que } \\
\text { se le han aportado. } \\
\text { Formula conclusiones } \\
\text { vagas o irrelevantes. }\end{array}$ & $\begin{array}{l}\text { Halla información } \\
\text { relativa a aspectos } \\
\text { clave en fuentes que } \\
\text { se le han aportado. } \\
\text { Formula algunas con- } \\
\text { clusiones relevantes. }\end{array}$ & $\begin{array}{l}\text { Halla información } \\
\text { relativa a aspectos } \\
\text { clave de numerosas } \\
\text { fuentes. } \\
\text { Formula conclusiones } \\
\text { relevantes apoyándose } \\
\text { en pruebas aportadas. }\end{array}$ & $\begin{array}{l}\text { Halla información } \\
\text { actualizada y relevante } \\
\text { relativa a aspectos } \\
\text { clave indagados en } \\
\text { fuentes contrastadas. } \\
\text { Formula conclusiones } \\
\text { relevantes apoyándose } \\
\text { en pruebas aportadas, } \\
\text { con argumentación } \\
\text { de estas. }\end{array}$ \\
\hline $\begin{array}{l}\text { 11. Coherencia y } \\
\text { relevancia de formula- } \\
\text { ciones. }\end{array}$ & $\begin{array}{l}\text { No realiza búsquedas } \\
\text { operativas y significa- } \\
\text { tivas. }\end{array}$ & $\begin{array}{l}\text { Realiza algunas bús- } \\
\text { quedas operativas y } \\
\text { significativas. }\end{array}$ & $\begin{array}{l}\text { Aporta búsquedas } \\
\text { operativas y significa- } \\
\text { tivas estableciendo su } \\
\text { relevancia. }\end{array}$ & $\begin{array}{l}\text { Aporta búsquedas } \\
\text { útiles y significativas } \\
\text { estableciendo su rele- } \\
\text { vancia y aplicabilidad } \\
\text { en otras situaciones. }\end{array}$ \\
\hline $\begin{array}{l}\text { 12. Valoración del } \\
\text { trabajo desarrollado. }\end{array}$ & $\begin{array}{l}\text { No confronta el resul- } \\
\text { tado alcanzado. } \\
\text { No analiza la pla- } \\
\text { nificación necesaria } \\
\text { para la realización del } \\
\text { trabajo. }\end{array}$ & $\begin{array}{l}\text { Confronta el resultado } \\
\text { alcanzado. } \\
\text { Analiza la planifica- } \\
\text { ción necesaria para la } \\
\text { realización del trabajo. }\end{array}$ & $\begin{array}{l}\text { Confronta el resultado } \\
\text { alcanzado y menta } \\
\text { aspectos que hay que } \\
\text { mejorar. } \\
\text { Analiza la planifica- } \\
\text { ción necesaria para la } \\
\text { realización del trabajo } \\
\text { exponiendo factores } \\
\text { que hay que contem- } \\
\text { plar en su puesta en } \\
\text { práctica. }\end{array}$ & $\begin{array}{l}\text { Confronta el resultado } \\
\text { alcanzado, haciendo } \\
\text { propuestas concretas } \\
\text { de mejora. } \\
\text { Analiza la planifica- } \\
\text { ción necesaria para } \\
\text { la realización del } \\
\text { trabajo proponiendo } \\
\text { estrategias concretas } \\
\text { de ejecución. }\end{array}$ \\
\hline $\begin{array}{l}\text { 13. Gestionar situa- } \\
\text { ciones presentadas } \\
\text { aplicando conoci- } \\
\text { miento adquirido y } \\
\text { haciendo propuestas } \\
\text { de actuación concre- } \\
\text { tas. }\end{array}$ & $\begin{array}{l}\text { Encuentra algunas } \\
\text { relaciones científicas } \\
\text { en las realidades expe- } \\
\text { rimentadas. }\end{array}$ & $\begin{array}{l}\text { Encuentra las } \\
\text { relaciones científicas } \\
\text { existentes en las reali- } \\
\text { dades experimentadas } \\
\text { utilizando de manera } \\
\text { no precisa el razona- } \\
\text { miento y la metodolo- } \\
\text { gía científica. }\end{array}$ & $\begin{array}{l}\text { Encuentra las } \\
\text { relaciones científicas } \\
\text { existentes en las reali- } \\
\text { dades experimentadas } \\
\text { utilizando correcta- } \\
\text { mente el razonamien- } \\
\text { to y la metodología } \\
\text { científica. }\end{array}$ & $\begin{array}{l}\text { Encuentra las relacio- } \\
\text { nes científicas existen- } \\
\text { tes en las realidades } \\
\text { experimentadas utili- } \\
\text { zando correctamente } \\
\text { el razonamiento y la } \\
\text { metodología científica } \\
\text { sugiriendo conclusio- } \\
\text { nes derivadas. }\end{array}$ \\
\hline $\begin{array}{l}\text { 14. Dar valor a la } \\
\text { realización de tareas } \\
\text { y/o cumplimiento de } \\
\text { objetivos. }\end{array}$ & $\begin{array}{l}\text { No considera impor- } \\
\text { tante la conclusión y } \\
\text { calidad del trabajo. }\end{array}$ & $\begin{array}{l}\text { Considera poco im- } \\
\text { portante la conclusión } \\
\text { y calidad del trabajo. }\end{array}$ & $\begin{array}{l}\text { Considera bastante } \\
\text { importante la con- } \\
\text { clusión y calidad del } \\
\text { trabajo. }\end{array}$ & $\begin{array}{l}\text { Considera muy im- } \\
\text { portante la conclusión } \\
\text { y calidad del trabajo. }\end{array}$ \\
\hline $\begin{array}{l}\text { 15.Tomar decisiones } \\
\text { por iniciativa propia } \\
\text { para ejecutar acciones } \\
\text { fundamentadas } \\
\text { asociadas a nuevas } \\
\text { situaciones. }\end{array}$ & $\begin{array}{l}\text { Actúa con poca auto- } \\
\text { nomía en contextos } \\
\text { diversos. }\end{array}$ & $\begin{array}{l}\text { Actúa con bastante } \\
\text { autonomía en contex- } \\
\text { tos diversos pero sin } \\
\text { cuestionarse las causas. }\end{array}$ & $\begin{array}{l}\text { Actúa autónomamen- } \\
\text { te en contextos diver- } \\
\text { sos, cuestionándose las } \\
\text { causas. }\end{array}$ & $\begin{array}{l}\text { Actúa autónoma- } \\
\text { mente en contextos } \\
\text { diversos, asumiendo } \\
\text { reflexivamente las } \\
\text { causas. }\end{array}$ \\
\hline
\end{tabular}




\begin{tabular}{|c|c|c|c|c|}
\hline Indicadores & Nivel 1 & Nivel 2 & Nivel 3 & Nivel 4 \\
\hline $\begin{array}{l}\text { 16. Planificar la } \\
\text { ejecución de tareas } \\
\text { propuestas con inicia- } \\
\text { tiva propia. }\end{array}$ & $\begin{array}{l}\text { Sigue normas estable- } \\
\text { cidas sin organizarse } \\
\text { en la realización del } \\
\text { trabajo acordado. }\end{array}$ & $\begin{array}{l}\text { Sigue normas estable- } \\
\text { cidas organizándose } \\
\text { para la realización del } \\
\text { trabajo acordado. }\end{array}$ & $\begin{array}{l}\text { Mejora normas esta- } \\
\text { blecidas para favorecer } \\
\text { la mejor organización } \\
\text { del trabajo. }\end{array}$ & $\begin{array}{l}\text { Aplica acciones alter- } \\
\text { nativas para alcanzar } \\
\text { más eficiencia en el } \\
\text { trabajo establecido. }\end{array}$ \\
\hline $\begin{array}{l}\text { 17. Presentar y anali- } \\
\text { zar datos pertinentes y } \\
\text { relevantes. }\end{array}$ & $\begin{array}{l}\text { Muestra información } \\
\text { relacionada con la } \\
\text { solicitada. }\end{array}$ & $\begin{array}{l}\text { Muestra información } \\
\text { relativa a aspectos } \\
\text { clave. }\end{array}$ & $\begin{array}{l}\text { Muestra y valora } \\
\text { información relativa a } \\
\text { aspectos clave. }\end{array}$ & $\begin{array}{l}\text { Muestra y valora in- } \\
\text { formación actualizada } \\
\text { relativa a aspectos } \\
\text { clave. }\end{array}$ \\
\hline $\begin{array}{l}\text { 18. Realizar, desde } \\
\text { sistemas informáticos, } \\
\text { acciones que permiten } \\
\text { extraer y/o presentar } \\
\text { información a través } \\
\text { de: } \\
\text { a) tablas, gráficos, etc., } \\
\text { b) imágenes, videos, } \\
\text { sonidos, } \\
\text { c) modificar/crear una } \\
\text { página web. }\end{array}$ & $\begin{array}{l}\text { Ejecuta correctamente } \\
\text { las acciones del aparta- } \\
\text { do a. }\end{array}$ & $\begin{array}{l}\text { Ejecuta correctamente } \\
\text { las acciones del aparta- } \\
\text { do a y algunas de } \\
\text { las acciones del apar- } \\
\text { tado b. }\end{array}$ & $\begin{array}{l}\text { Ejecuta correctamente } \\
\text { las acciones de los } \\
\text { apartados a y b. }\end{array}$ & $\begin{array}{l}\text { Ejecuta correctamente } \\
\text { las acciones de los } \\
\text { apartados a y b y } \\
\text { algunas de las acciones } \\
\text { del apartado c. }\end{array}$ \\
\hline $\begin{array}{l}\text { 19. Realizar actuacio- } \\
\text { nes concretas como: } \\
\text { a) enviar mensajes } \\
\text { electrónicos y/o } \\
\text { participar en un chat; } \\
\text { b) adjuntar ficheros } \\
\text { y/o incluir enlaces; c) } \\
\text { utilizar un buscador, } \\
\text { d) descargar imágenes, } \\
\text { vídeos, sonidos. }\end{array}$ & $\begin{array}{l}\text { Ejecuta correctamente } \\
\text { las acciones del aparta- } \\
\text { do a. }\end{array}$ & $\begin{array}{l}\text { Ejecuta correctamente } \\
\text { las acciones de los } \\
\text { apartados a y b. }\end{array}$ & $\begin{array}{l}\text { Ejecuta correctamente } \\
\text { las acciones de los } \\
\text { apartados a, b y c. }\end{array}$ & $\begin{array}{l}\text { Ejecuta todas las ac- } \\
\text { ciones correctamente. }\end{array}$ \\
\hline
\end{tabular}

Los resultados de aplicar los criterios recogidos en el cuadro 6 a la observación de los alumnos de la muestra durante el desarrollo de las actividades 1, 2 y 3, dieron lugar a los datos recogidos en la tabla 2. En ellos, se muestra un patrón de desarrollo bastante regular en el alumnado, en el sentido de que en aquellos casos en los que alcanzaban niveles más altos estos valores se obtenían en todas las tareas, e igualmente ocurría respecto a los niveles bajos.

Tabla 2.

Niveles en la adquisición de competencias (actividades 1, 2 y 3 )

\begin{tabular}{|c|c|c|c|c|c|c|c|c|c|c|c|c|c|c|c|c|}
\hline \multirow{2}{*}{ Competencia valorada } & \multicolumn{4}{|c|}{ Alumno 1} & \multicolumn{4}{|c|}{ Alumno 2} & \multicolumn{4}{|c|}{ Alumno 3} & \multicolumn{4}{|c|}{ Alumno 4} \\
\hline & 1 & 2 & 3 & 4 & 1 & 2 & 3 & 4 & 1 & 2 & 3 & 4 & 1 & 2 & 3 & 4 \\
\hline 1. Comprensión lectora & & & $\mathrm{x}$ & & & & $\mathrm{x}$ & & & $\mathrm{x}$ & & & & $\mathrm{x}$ & & \\
\hline $\begin{array}{l}\text { 2. Exposición y argumentación verbal } \\
\text { de ideas }\end{array}$ & & & $\mathrm{x}$ & & & & $\mathrm{x}$ & & & $\mathrm{x}$ & & & & $\mathrm{x}$ & & \\
\hline 3. Comunicación escrita & & & $\mathrm{x}$ & & & & $\mathrm{x}$ & & $\mathrm{x}$ & & & & $\mathrm{x}$ & & & \\
\hline $\begin{array}{l}\text { 4. Aplicar conocimientos en contextos } \\
\text { diversos }\end{array}$ & & & & $\mathrm{x}$ & & & $\mathrm{x}$ & & & $\mathrm{x}$ & & & & $\mathrm{x}$ & & \\
\hline $\begin{array}{l}\text { 5. Analizar y sintetizar informaciones } \\
\text { de textos }\end{array}$ & & & $\mathrm{x}$ & & & & $\mathrm{x}$ & & & $\mathrm{x}$ & & & & $\mathrm{x}$ & & \\
\hline
\end{tabular}




\begin{tabular}{|c|c|c|c|c|c|c|c|c|c|c|c|c|c|c|c|c|}
\hline \multirow{2}{*}{ Competencia valorada } & \multicolumn{4}{|c|}{ Alumno 1} & \multicolumn{4}{|c|}{ Alumno 2} & \multicolumn{4}{|c|}{ Alumno 3} & \multicolumn{4}{|c|}{ Alumno 4} \\
\hline & 1 & 2 & 3 & 4 & 1 & 2 & 3 & 4 & 1 & 2 & 3 & 4 & 1 & 2 & 3 & 4 \\
\hline $\begin{array}{l}\text { 6. Analizar y extraer información } \\
\text { de tablas y gráficos }\end{array}$ & & & $\mathrm{x}$ & & & & $\mathrm{x}$ & & $\mathrm{x}$ & & & & & $\mathrm{x}$ & & \\
\hline 7. Trabajar en equipo & & & $\mathrm{x}$ & & & & & $\mathrm{x}$ & & $\mathrm{x}$ & & & & & $\mathrm{x}$ & \\
\hline $\begin{array}{l}\text { 8. Mostrar conocimientos básicos y } \\
\text { específicos }\end{array}$ & & & $\mathrm{x}$ & & & & $\mathrm{x}$ & & & $\mathrm{x}$ & & & & $\mathrm{x}$ & & \\
\hline 9. Investigación: establecer relaciones & & & $\mathrm{x}$ & & & & $\mathrm{x}$ & & $\mathrm{x}$ & & & & & $\mathrm{x}$ & & \\
\hline 10. Investigación: realizar búsquedas & & & & $\mathrm{x}$ & & & $\mathrm{x}$ & & & $\mathrm{x}$ & & & & $\mathrm{x}$ & & \\
\hline $\begin{array}{l}\text { 11. Investigación: formular } \\
\text { conclusiones }\end{array}$ & & & $\mathrm{x}$ & & & $\mathrm{x}$ & & & $\mathrm{x}$ & & & & $\mathrm{x}$ & & & \\
\hline 12. Preocupación por la calidad & & & $\mathrm{x}$ & & & & $\mathrm{x}$ & & $\mathrm{x}$ & & & & $\mathrm{x}$ & & & \\
\hline 13. Adaptación a nuevas situaciones & & & $\mathrm{x}$ & & & & $\mathrm{x}$ & & $\mathrm{x}$ & & & & $\mathrm{x}$ & & & \\
\hline 14. Motivación de logro & & $\mathrm{x}$ & & & & & $\mathrm{x}$ & & & $\mathrm{x}$ & & & & $\mathrm{x}$ & & \\
\hline 15. Creatividad & & & & $\mathrm{x}$ & & & $\mathrm{x}$ & & $\mathrm{x}$ & & & & $\mathrm{x}$ & & & \\
\hline $\begin{array}{l}\text { 16. Autonomía en el desarrollo de } \\
\text { actividades }\end{array}$ & & & $\mathrm{x}$ & & & & $\mathrm{x}$ & & $\mathrm{x}$ & & & & $\mathrm{x}$ & & & \\
\hline 18. Gestión de la información & & & $\mathrm{x}$ & & & & $\mathrm{x}$ & $\mathrm{x}$ & & & & & & $\mathrm{x}$ & & \\
\hline $\begin{array}{l}\text { 19. Conocimiento práctico de aplica- } \\
\text { ciones con ordenador }\end{array}$ & & & $\mathrm{x}$ & & & & & $\mathrm{x}$ & & & $\mathrm{x}$ & & & & $\mathrm{x}$ & \\
\hline
\end{tabular}

\section{Actividades con ordenador}

La realización y el seguimiento de las actividades 4 y 5 requirieron la colaboración de un grupo de alumnos de otro instituto, del mismo curso, pero ubicado en distinta zona de la ciudad. Estas dos actividades no han estado guiadas por la profesora y tampoco han sido objeto de prueba piloto. Esto nos permite considerar que las competencias que los alumnos ponen en juego resultan de la transferencia de las que han podido desarrollar en las tres actividades anteriores.

Cada grupo elaboró su propia propuesta de plan para la gestión del tráfico de una zona cercana a su centro. Plan de calidad atmosférica de zona. En estos planes, se incluían los siguientes aspectos:

a) identificación de la zona de estudio y de sus características geográficas y urbanísticas.

b) Identificación de contaminantes presentes.

c) Tipo de contaminación de la zona.

d) Valoración de la densidad del tráfico de vehículos a motor con elaboración de tablas por zonas y horario.

e) Propuesta de actuaciones para aminorar/solventar problemas detectados.

Los grupos intercambiaron sus propuestas de forma que cada grupo analizó y valoró el plan del otro. Seguidamente, se celebró una sesión conjunta de chat en horario lectivo y también mediante correo electrónico personal en horario extraescolar.

En el intercambio mediante chat, se ponen de manifiesto, en las palabras de los propios alumnos junto con algunas competencias, algunos aspectos clave en los objetivos perseguidos con estas actividades, como son las actitudes y los valores que se ejemplifican en los registros de los alumnos:

1. Relaciones entre factores que influyen en la contaminación.

«... El secreto para no contaminar más es no derrochar las fuentes de energía...» (alumno 4).

«... El problema real de la contaminación es el consumismo...» (alumno 1). 
2. Preocupación por la calidad y las valoraciones del trabajo o de su proceso de realización.

«¿Os parece bien nuestro trabajo?, ¿os parecen bien nuestras medidas?...» (alumno 1).

«... Vuestro trabajo estaba bastante completito, ¿¿ónde habéis buscado información para el trabajo?...» (alumno 3).

“¿Cómo habéis contado el número de coches?...» (alumno 4).

3. Búsqueda del contraste con las opiniones de los demás.

«... ¿Dónde habéis buscado información para el trabajo...». «¿Veis interesante esta forma de intercambiar opiniones?..." (alumno 3).

«¿Os gusta esta forma de trabajar? Yo la veo buena, es entretenido esto de intercambiar opiniones...» (alumno 2).

4. Autovaloración.

«No tenemos suficientes datos de contaminación atmosférica en nuestra zona...» (alumno 1).

«Nuestro trabajo es parco pero completo» (alumno 2).

5. Compromiso ético.

«... Deberíamos cuidar más las zonas verdes...» (alumno 1 ).

«... Se deberían quitar los carnets de conducir a los 14 años ya que son muy niños para ir en una moto...».

«... El problema real de la contaminación es la conciencia social...» (alumno 2).

6. Espíritu crítico y emprendedor.

«... Hay que ir al Ayuntamiento y protestar con fundamento...» (alumno 2).

«El Ayuntamiento pasa del tema». «... Hay que hacer lo que sea ya y movilizar a la gente...». «... Hay que recoger firmas y encadenarse...» (alumno 4).

Los niveles asignados al desarrollo del alumnado mediante la realización de las actividades se muestran en la tabla 3.

Tabla 3.

Niveles en la adquisición de competencias (actividades 4 y 5)

\begin{tabular}{|c|c|c|c|c|c|c|c|c|c|c|c|c|c|c|c|c|}
\hline \multirow{2}{*}{ Competencia valorada } & \multicolumn{4}{|c|}{ Alumno 1} & \multicolumn{4}{|c|}{ Alumno 2} & \multicolumn{4}{|c|}{ Alumno 3} & \multicolumn{4}{|c|}{ Alumno 4} \\
\hline & 1 & 2 & 3 & 4 & 1 & 2 & 3 & 4 & 1 & 2 & 3 & 4 & 1 & 2 & 3 & 4 \\
\hline 1. Comprensión lectora & & & $\mathrm{x}$ & & & & $\mathrm{x}$ & & & $\mathrm{x}$ & & & & $\mathrm{x}$ & & \\
\hline $\begin{array}{l}\text { 2. Exponer y argumentar ideas verbal- } \\
\text { mente }\end{array}$ & & & & $\mathrm{x}$ & & & $\mathrm{x}$ & & $\mathrm{x}$ & & & & & $\mathrm{x}$ & & \\
\hline 3. Comunicación escrita & & & $\mathrm{x}$ & & & & $\mathrm{x}$ & & $\mathrm{x}$ & & & & $\mathrm{x}$ & & & \\
\hline $\begin{array}{l}\text { 4. Aplicar conocimientos en contextos } \\
\text { diversos }\end{array}$ & & & & $\mathrm{x}$ & & & $\mathrm{x}$ & & & $\mathrm{x}$ & & & & & $\mathrm{x}$ & \\
\hline $\begin{array}{l}\text { 5. Analizar y sintetizar } \\
\text { informaciones de textos }\end{array}$ & & & & $\mathrm{x}$ & & & $\mathrm{x}$ & & $\mathrm{x}$ & & & & & $\mathrm{x}$ & & \\
\hline $\begin{array}{l}\text { 6. Extraer y analizar información de } \\
\text { tablas y gráficos }\end{array}$ & & & $\mathrm{x}$ & & & & & $\mathrm{x}$ & & $\mathrm{x}$ & & & & $\mathrm{x}$ & & \\
\hline 7. Trabajar en equipo & & & $\mathrm{x}$ & & & & & $\mathrm{x}$ & & $\mathrm{x}$ & & & & & $\mathrm{x}$ & \\
\hline $\begin{array}{l}\text { 8. Mostrar conocimientos básicos y } \\
\text { específicos }\end{array}$ & & & & $\mathrm{x}$ & & & $\mathrm{x}$ & & & $\mathrm{x}$ & & & & $\mathrm{x}$ & & \\
\hline $\begin{array}{l}\text { 9. Investigación: establecer } \\
\text { relaciones }\end{array}$ & & & $\mathrm{x}$ & & & & $\mathrm{x}$ & & $\mathrm{x}$ & & & & & $\mathrm{x}$ & & \\
\hline 10. Investigación: realizar búsquedas & & & & $\mathrm{x}$ & & & & $\mathrm{x}$ & & $\mathrm{x}$ & & & & $\mathrm{x}$ & & \\
\hline $\begin{array}{l}\text { 11. Investigación: formular } \\
\text { conclusiones }\end{array}$ & & & & $\mathrm{x}$ & & & & $\mathrm{x}$ & & $\mathrm{x}$ & & & & $\mathrm{x}$ & & \\
\hline
\end{tabular}




\begin{tabular}{|c|c|c|c|c|c|c|c|c|c|c|c|c|c|c|c|c|}
\hline \multirow{2}{*}{ Competencia valorada } & \multicolumn{4}{|c|}{ Alumno 1} & \multicolumn{4}{|c|}{ Alumno 2} & \multicolumn{4}{|c|}{ Alumno 3} & \multicolumn{4}{|c|}{ Alumno 4} \\
\hline & 1 & 2 & 3 & 4 & 1 & 2 & 3 & 4 & 1 & 2 & 3 & 4 & 1 & 2 & 3 & 4 \\
\hline 12. Preocupación por la calidad & & & $\mathrm{x}$ & & & & $\mathrm{x}$ & & & $\mathrm{x}$ & & & & $\mathrm{x}$ & & \\
\hline 13. Adaptación a nuevas situaciones & & & $\mathrm{x}$ & & & $\mathrm{x}$ & & $\mathrm{x}$ & & & & $\mathrm{x}$ & & & & \\
\hline 14. Motivaciones de logro & & & $\mathrm{x}$ & & & & $\mathrm{x}$ & & $\mathrm{x}$ & & & & $\mathrm{x}$ & & & \\
\hline 15. Creatividad & & & $\mathrm{x}$ & & & & $\mathrm{x}$ & & $\mathrm{x}$ & & & & $\mathrm{x}$ & & & \\
\hline $\begin{array}{l}\text { 16. Autonomía en el desarrollo de } \\
\text { actividades }\end{array}$ & & & $\mathrm{x}$ & & & & $\mathrm{x}$ & & $\mathrm{x}$ & & & & & $\mathrm{x}$ & & \\
\hline 17. Gestión de la información & & & & $\mathrm{x}$ & & & $\mathrm{x}$ & & & $\mathrm{x}$ & & & & $\mathrm{x}$ & & \\
\hline $\begin{array}{l}\text { 18. Conocimiento práctico de aplica- } \\
\text { ciones con ordenador }\end{array}$ & & & $\mathrm{x}$ & & & & & $\mathrm{x}$ & & $\mathrm{x}$ & & & & & $\mathrm{x}$ & \\
\hline $\begin{array}{l}\text { 19. Habilidades derivadas del uso de } \\
\text { Internet }\end{array}$ & & & $\mathrm{x}$ & & & & $\mathrm{x}$ & & & $\mathrm{x}$ & & & & & $\mathrm{x}$ & \\
\hline
\end{tabular}

A la vista de los datos de las tablas 2 y 3 , se aprecia el mismo patrón de desarrollo en todas las actividades. Así, de los cuatro alumnos, alcanzan niveles de adquisición competenciales medio-altos el alumno 1 y el alumno 2, mientras que el alumno 4 se mantenía en una franja media y el alumno 3 continuaba en un nivel menor.

\section{CONCLUSIONES Y DISCUSIÓN}

Consideramos que las actividades utilizadas han conseguido movilizar competencias en el alumnado, aunque no todas han alcanzado el mismo nivel de desarrollo. En muy buena medida, se han puesto en juego la disposición y la iniciativa del alumnado para investigar el entorno; se ha potenciado el trabajo en equipo y aprovechado las oportunidades que ofrece; se ha fomentado la búsqueda de información y el uso de Internet y, especialmente, se han obtenido evidencias referidas a la capacidad crítica del alumnado y a su compromiso ético.

Valoramos positivamente el haber promovido, en el alumnado, una reflexión propia sobre la importancia del problema desde una perspectiva personal y social que esperamos les faculte para comprometerse. Esta conclusión queda reforzada por las evidencias obtenidas en el chat, donde el alumnado trabaja con autonomía en un entorno no normalizado e interaccionando entre iguales.

Además de los datos de las tablas 2 y 3 , las observaciones y las entrevistas en el aula ponen de manifiesto que el alumnado que muestra mayor grado de desarrollo en mayor número de competencias (alumnos 1 y 2) iniciaban al grupo en la discusión, definición y el análisis de tareas e informes (competencias 2,5 y 7), lo que contribuía a que el resto se sumara y participara activamente gracias a ese empuje inicial. De esta manera, unos ejercían un liderazgo positivo sobre otros a la hora de sintetizar información, proponer ideas y analizar las tareas colectivamente. Esto promovía a su vez una dinámica de acción que fomentaba la incorporación en la realización de las actividades y obtención de objetivos del resto del grupo, así como en la discusión y elaboración de informes. De ahí que aquellas competencias que están muy relacionadas con la colaboración y el trabajo en grupo (7 y 14) muestren un nivel de desarrollo similar en todos los alumnos, independientemente de su nivel de aprovechamiento en otras competencias. Esto nos lleva a considerar que las actividades resultan especialmente adecuadas para su desarrollo en «todo» el alumnado.

Las competencias que alcanzan un menor desarrollo (desde la 11 hasta la 16) aparecen ligadas a: en primer lugar, la aplicación del conocimiento (por ejemplo, en las relaciones que establecen entre «vehículos a motor-comodidad», "vehículos a motor-libertad de elección» y «vehículos a motor-con- 
taminación» y la formulación de conclusiones sobre estas relaciones); en segundo lugar, el aprendizaje de conocimientos complementarios (por ejemplo, contaminantes secundarios (lluvia ácida o diferentes tipos de smog), y por último, la autonomía en las búsquedas de información y en el desarrollo de las actividades.

A la hora de argumentar ideas, en los componentes de perfil de desarrollo competencial más bajo (alumnos 3 y 4) se ponían especialmente de manifiesto las dificultades, especialmente en lo que se refiere al análisis y la sintesis de información y la formulación de conclusiones, la aplicación del conocimiento y establecer relaciones entre factores que cabe contemplar. Todos estos aspectos se confirmaron en las puestas en común realizadas sobre los informes elaborados de los planes de zona y en las observaciones de las sesiones lectivas. Estas insuficiencias se muestran, asimismo, en la calidad de la expresión escrita utilizada en los trabajos. Sin embargo, se ha apreciado en el alumnado una conciencia sobre sus propias dificultades manifestada en sus comentarios mostrando preocupación por la calidad de estos.

En suma, el trabajo realizado nos permite diagnosticar zonas concretas en las que se hace necesario reforzar e insistir, así como necesidades específicas en cada estudiante. También nos ha mostrado aspectos concretos en los que el trabajo en equipo resulta realmente recomendable. Esto nos anima a continuar en la misma línea.

\section{REFERENCIAS BIBLIOGRÁFICAS}

BANet, E. (2007). Finalidades de la educación científica en secundaria: opinión del profesorado sobre la situación actual. Enseñanza de las Ciencias, 25 (1), pp. 5-20.

Banet, E. (2010). Finalidades de la educación científica en educación secundaria: aportaciones de la investigación educativa y opinión de los profesores. Enseñanza de las Ciencias, 28 (2), pp. 199-214.

Boyano, J., B. Gordo, T. Lupión, J. M. Cirre y M. L. Ruiz (2005). La Contaminación. Material de trabajo para el aula de secundaria no publicado.

Consejería Educación Junta de Andalucía (CEJA) (2007). Orden de agosto de 2007, por la que se desarrolla el currículo correspondiente a la Educación Secundaria Obligatoria en Andalucía. (BOJA 5 de enero de 2007).

Cañas, A., M. J. Martín-Díaz y J. Nieda (2007). Competencia en el conocimiento e interacción con el mundo físico. La competencia cientifica, Madrid: Alianza.

Deboer, G. (2000). Scientific literacy: Another look at its historical and contemporary meanings and its relationship to science education reform. Journal of Research in Science Teaching, 37(6), pp. 582-601. http://dx.doi.org/10.1002/1098-2736(200008)37:6<582::AID-TEA5>3.0.CO;2-L

España, E. y T. Prieto (2010). Los problemas socio-científicos como contexto para la enseñanza y el aprendizaje de las ciencias. Investigación en la Escuela, 71, pp. 19-24.

Fensham, P. (2002). Time to change drivers for scientific literacy. Canadian Journal of Science, Mathematics and Technology Education, 2(1), pp. 9-24.

http://dx.doi.org/10.1080/14926150209556494

Holbrook, J. y M. Rannikmae (2007). The Nature of Science Education for Enhancing Scientific Literacy. International Journal of Science Education, 29 (11), pp. 1347-1362.

http://dx.doi.org/10.1080/09500690601007549

JENKINS, E. (1999). School science, citizenship and the public understanding of science. International Journal of Science Education, 21, pp. 703-710.

http://dx.doi.org/10.1080/095006999290363

Lupión, T. y T. Prieto (2005). Actividades CTS: análisis de competencias. Enseñanza de las Ciencias. Número Extra VII Congreso. En Cd (6 páginas). Granada. España. 
Lupión, T. y T. Prieto (2006). «Oportunidades de aprendizaje mediante una actividad CTS con el uso de TIC: la calidad del aire en la ciudad». En: A. Blanco, V. Brero, M. A. Jiménez y T. Prieto (Coord.). Las Relaciones CTS en la Educación Científica. Área de Conocimiento de Didáctica de las Ciencias Experimentales. Universidad de Málaga. Málaga.

Lupión, T. y T. Prieto (2007). "Actividades CTS. Un ejemplo para el desarrollo de competencias propias de la educación para la ciudadanía y la alfabetización científica». Cooperación Educativa, 85 , pp. 23-26.

MEC (2007). Real Decreto 1631/2006 de 29 de diciembre por el que se establecen las enseñanzas mínimas correspondientes a la Educación Secundaria Obligatoria (BOE 5 de enero de 2007).

Millar, R. (2006). Twenty First Century Science: Insights from the design and implementation of a scientific literacy approach in school science. International Journal of Science Education, 28(13), pp. 1499-1521.

http://dx.doi.org/10.1080/09500690600718344

OECD (2007a). OECD Programme for International Student Assessment (PISA). Consultado en http:/ /www.pisa.oecd.org en junio de 2009.

OECD (2007b). PISA (2006). Science competencies for tomorrow's world, París: OECD.

Prieto, T. y E. España (2010). Educar para la sostenibilidad. Un problema del que podemos hacernos cargo. Revista Eureka sobre Enseñanza y Divulgación de las Ciencias, 7 (número extraordinario), pp. 216-229.

Prieto, T., E. España y C. Martín (2012). Algunas cuestiones relevantes en la enseñanza de las ciencias desde una perspectiva Ciencia-Tecnología-Sociedad. Revista Eureka sobre Enseñanza y Divulgación de las Ciencias, 9 (1), pp. 71-77.

Ratcliffe, M. (1997). Pupil decision-making about socio-scientific issues within the science curriculum. International Journal of Science Education, 19(2), pp. 167-182. http://dx.doi.org/10.1080/0950069970190203

Roth, W. M. y S. Lee (2004). Science education as/for participation in the community. Science Education, 88 , pp. 263-291. http://dx.doi.org/10.1002/sce.10113

SADLER, T. D. (2009). Situated learning in science education: socio-scientific issues as contexts for practice. Studies in Science Education, 45(1), pp. 1-42. http://dx.doi.org/10.1080/03057260802681839

Sadler, T. D. y D. L. Zeidler (2009). Scientific Literacy, PISA, and Socio-scientific Discourse: Assessment for Progressive Aims of Science Education. Journal of Research on Science Teaching, 46 (8), pp. 909-921.

http://dx.doi.org/10.1002/tea.20327

SAuvé, L. (2010). Educación científica y educación ambiental: un cruce fecundo. Enseñanza de las Ciencias, 28(1), pp. 5-18.

Schibeci, R. y L. LeE (2003). Portrayals of science and scientists, and «Science for Citizenship». Research in Science \& Technological Education, 21(2), pp. 177-192. http://dx.doi.org/10.1080/0263514032000127220

Thomas, J. (2000). Using current controversies in the classroom: Opportunities and concerns. Melbourne Studies in Education, 41(2), pp. 133-144. http://dx.doi.org/10.1080/17508480009556366

WWF/ADENA y Consejerías de EduCación y Ciencia y Medio Ambiente de la Junta de AndaLuCíA (1998). Explorando el Medio Ambiente Europeo. Programa ALDEA de Educación Ambiental. Agencia Europea del Medio Ambiente. 


\title{
Air pollution: a context for the development of competencies in the secondary classroom
}

\author{
Teresa Lupión Cobos \\ Facultad de Ciencias de la Educación. Universidad de Málaga \\ teluco@uma.es \\ Teresa Prieto Ruz \\ Facultad de Ciencias de la Educación. Universidad de Málaga \\ ruz@uma.es
}

This paper studies the progression in the learning process of a group of students aged 16 to 18 , based on a classroom research. The students were in their first year of higher education. The topic chosen was close and interesting to them:"The air quality in cities" and it was articulated in a sequence of activities.

The approach considers it is necessary to use specific problems that can be found in the students' environment and hence to promote critical thinking and establish the necessary inter-linkages from an interdisciplinary and inclusive perspective.

The methodology is focused on the students as the main players of their own learning process, and on the work of the teacher as a facilitator, coordinator and evaluator. This unit has been inserted in the development of an optional subject with an STS approach, within the content block "Social impact of scientific and technological development", incorporating aspects related to "The direct impact on the environment" and "The social control of scientific and technological activity".

Five activities were used in which students had to: analyze information about the quality of the air; identify problems and make suggestions to reduce air pollution in their immediate environment. The work results of the groups were exchanged through the network with those from students in other schools. This allowed them to compare various proposals and to assess the different contributions.

The implementation of the unit was conducted in the second quarter of the academic year, once the student is familiar with the work methodology and has incorporated basic contents related to Science from a technological and social approach.

This study sought to know, analyze and describe the learning that students achieve, expressed according to the competences that come into play with the teaching process and the above materials. We have tried to answer the following questions:

1. What opportunities do the activities proposed offer for the development of competences in students?

2. What is the progression in the competences of a group of students after carrying out these activities?

The teaching and learning process was developed using selected materials, which were specifically designed to address this problem. The collection of information during the development of the teaching was carried out through:

- Observation protocols of in the classroom

- Records of information exchanges between students from different schools

- Interviews

Observation protocols design was guided by the perception of researchers on the skills involved in the activities and a pilot test assessing the students' competences brought into play in the activities selected.

They took into account the actions the students performed on every process of each activity. Based on this, they defined indicators for the competences considered and 4 levels of development in each of them. The results show that these activities have succeeded in mobilizing competences in students, although not all of them have reached the same level of development.

The competences where higher levels of achievement have been found are: teamwork, information search and use of the Internet, critical thinking and ethical commitment. It is also necessary to encourage students to reflect on the importance of the problem, from a personal and social perspective. This conclusion is reinforced by the evidence observed in the chat, where the student has worked with autonomy in a non-standard environment and interacting among equals. 